\title{
Risks of Subarachnoid Hemorrhage in Siblings: A Nationwide Epidemiological Study from Sweden
}

\author{
Jan Sundquist ${ }^{\mathrm{a}}$ Xinjun $\mathrm{Li}^{\mathrm{a}}$ Kristina Sundquist $^{\mathrm{a}}$ Kari Hemminki $^{\mathrm{a}, \mathrm{b}}$ \\ a Center for Family and Community Medicine, Karolinska Institutet, Huddinge, Sweden; ${ }^{\mathrm{b}}$ Division of Molecular \\ Genetic Epidemiology, German Cancer Research Center (DKFZ), Heidelberg, Germany
}

\section{Key Words}

Subarachnoid hemorrhage - Family history • Sibling risk • Hereditary factors

\section{Abstract}

This nationwide study aimed to enhance available data by determining sibling risks of subarachnoid hemorrhage in a total population. The MigMed database at the Karolinska Institute, Stockholm, was used to identify all cases of subarachnoid hemorrhage diagnosed in Sweden between 1987 and 2001. Incidence ratios standardized for age, region, and socioeconomic status (SIRs) were calculated for persons with at least 1 sibling with subarachnoid hemorrhage. The reference group consisted of persons whose siblings had no subarachnoid hemorrhage. A total of 90 affected siblings were identified; their SIR of subarachnoid hemorrhage was 2.75 . The risk decreased with increasing age in both men and women. Within the limits of the sample size, no sex differences could be observed. The relatively high sibling risks are likely to be due to heritable causes and shared environmental factors. Genetic causes possibly weigh more in early- than late-onset cases. This study shows the feasibility of carrying out nationwide family studies on subarachnoid hemorrhage.

Copyright $\odot 2007$ S. Karger AG, Basel
\end{abstract}

\section{Introduction}

Subarachnoid hemorrhages account for 3\% [1] to $10 \%$ $[2,3]$ of all strokes. They often strike in middle age and have devastating consequences, accounting for more than a quarter of potential life years lost due to stroke [4]. The rate of subarachnoid hemorrhage has been decreasing annually, possibly because of the increased rate of CT scanning $[2,3]$. However, according to van Gijn and Rinkel [2] 'any apparent decrease is attributable to a higher rate of CT scanning, by which other haemorrhagic conditions are excluded'.

The mortality rate from subarachnoid hemorrhage is high. About 2 in 5 patients hospitalized for subarachnoid hemorrhage die within 1 month, and more than a third of survivors have serious disabilities [3]. The economic and emotional costs of subarachnoid hemorrhage for families, the health care system, and society at large are tremendous $[1,5]$.

In addition to other prevalent risk factors such as smoking [2, 6], alcohol consumption [6, 7], hypertension [6-8], high hyperglycemia, and excessive weight [9], inheritance plays a role in the etiology of subarachnoid hemorrhage. Previous studies have shown that first-degree relatives of patients with subarachnoid hemorrhage have a higher risk of developing subarachnoid hemorrhage than the general population [10-15]. One of these

Dr. Jan Sundquist

Center for Family and Community Medicine, Karolinska Institutet Alfred Nobels allé 12

SE-14183 Huddinge (Sweden)

Tel. +46 8524887 10, Fax +46 852486 06, E-Mail jan.sundquist@ki.se

\begin{tabular}{ll}
\hline KARGER & ( 2007 S. Karger AG, Basel \\
Fax +41613061234 & \\
$\begin{array}{l}\text { E-Mail karger@karger.ch } \\
\text { www.karger.com }\end{array}$ & $\begin{array}{l}\text { Accessible online at: } \\
\text { www.karger.com/ned }\end{array}$
\end{tabular}


studies was based on data from a nationwide database in Scotland [11]. About $80-90 \%$ of all cases of subarachnoid hemorrhage are due to the rupture of an intracerebral aneurysm [16], and close relatives of persons with intracerebral aneurysms develop such aneurysms more often than those whose close relatives do not have the condition $[15,16]$.

Numerous family studies have been undertaken on subarachnoid hemorrhage, including descriptive case series analysis, prevalence, case-control, and cohort incidence studies $[3,10-15,17,18]$. In all but two studies, identification of relatives who had also experienced subarachnoid hemorrhage was based on self-report, which can be subject to recall and selection biases and thus render quantitative estimates imprecise. We believe that using population-based multigenerational hospital-based registers to identify familial cases of subarachnoid hemorrhage provides less opportunity for selection bias and avoids recall bias.

In order to estimate incidence rates and sibling risks of subarachnoid hemorrhage in an unbiased setting, we linked nationwide individual-level data from the Swedish multigeneration register to nationwide individual-level data on medically diagnosed subarachnoid hemorrhage. The Swedish multigeneration register has been validated and used extensively in the study of familial cancer [1922]. Reliable data on sibling risks of a potentially fatal disease such as subarachnoid hemorrhage are of particular importance for clinical counseling and targeted surveillance.

\section{Methods}

\section{Research Database}

The research data used in this study were retrieved from the MigMed database, which was constructed using several national Swedish data registers. Information retrieved from the various registers was linked at the individual level via the national 10 digit civic registration number assigned to each person in Sweden for his or her lifetime. Prior to inclusion in the MigMed database, civic registration numbers were replaced by serial numbers to ensure the anonymity of all individuals.

Data used in this study were retrieved from a number of national registers in the MigMed database. Statistics Sweden, the Swedish government-owned statistics bureau, provided the multigeneration register. This register lists the parents (first generation) of persons (second generation and beyond) born in Sweden in 1932 or thereafter. All persons born in Sweden are entered in this register shortly after birth; a total of approximately 11 million individuals are listed in this register. Families were defined by linking children and parents to each other via the serial numbers.

Subarachnoid Hemorrhage in Siblings
Data also were retrieved from the cause of death register and the national census; the latter was used to obtain information on individual socioeconomic status. Finally, individual-level data on hospital diagnoses of subarachnoid hemorrhage were obtained from the Swedish hospital discharge register. Since 1986, complete data on all discharges, with dates of hospitalization and diagnoses, have been linked in this register. The register is of high quality and has few missing variables $[23,24]$.

Outcome Variable: Subarachnoid Hemorrhage Morbidity and Mortality

ICD-9 code 430 and ICD-10 code I60 from the 9th and 10th revisions of the International Classification of Diseases, respectively, were used to define subarachnoid hemorrhage morbidity (i.e., hospital diagnoses of subarachnoid hemorrhage) and mortality (i.e., subarachnoid hemorrhage listed as cause of death in the cause of death register).

\section{Individual Variables}

Individual variables included sex, age at diagnosis of subarachnoid hemorrhage, socioeconomic status of the men and women, and geographic region. Age at diagnosis of subarachnoid hemorrhage was divided into five categories: $<30,30-39,40-49$, $50-59$, and 60-69.

In this study, we chose to use occupational status as a possible indicator for socioeconomic status because of the association between low occupational status and coronary heart disease [25, 26]. Statistics Sweden, the Swedish governmental statistics bureau, uses a socioeconomic classification system based on occupation, which they developed in 1974 and revised in 1982 and 1984 [27]. This system was used to classify socioeconomic status in the current study. Occupations of persons in the economically active sector of the population were divided into different categories, which were constructed by combining occupations in which individuals had the same type of working situations. Prestige of individual jobs was not taken into account when constructing the categories. Occupational status of the men and women was thus divided into five categories: (1) manual workers; (2) lower level employees; (3) middle level employees and professionals; (4) the self-employed and farmers, and (5) all others. Young persons and students without an occupation were categorized based on their father's or mother's occupation; if that was not possible, they were included in the all others category. In addition, persons without paid employment were also included in the all others category.

Geographic region was divided into (1) big cities (cities with a population of more than 200,000, i.e., Stockholm, Gothenburg, and Malmö); (2) Southern Sweden, and (3) Northern Sweden. Sweden is divided into 25 counties. The border between Northern and Southern Sweden has traditionally been drawn at the Dalälven River. Therefore, all counties north of that river were defined as part of Northern Sweden. Geographic region was included as an independent variable to adjust for regional differences in hospital admissions for subarachnoid hemorrhage.

\section{Statistical Analysis}

Person-years were calculated from the start of follow-up, January 1,1987 , until subarachnoid hemorrhage diagnosis, death, emigration, or the end of study, December 31,2001. The follow-up period was divided into five 5 -year periods. Based on the European standard population, age-standardized incidence ratios 
Table 1. Incidence rates of subarachnoid hemorrhage in men and women aged 0-69 years

\begin{tabular}{|c|c|c|c|c|c|c|c|c|}
\hline \multirow{3}{*}{$\begin{array}{l}\text { Age at } \\
\text { diagnosis }\end{array}$} & \multicolumn{4}{|l|}{ Men } & \multicolumn{4}{|c|}{ Women } \\
\hline & \multicolumn{2}{|c|}{ all men } & \multicolumn{2}{|c|}{ men with sibling history } & \multicolumn{2}{|c|}{ all women } & \multicolumn{2}{|c|}{ women with sibling history } \\
\hline & $\mathrm{n}$ & $\begin{array}{l}\text { incidence rates } \\
\text { (per } 100,000 \\
\text { person-years) }\end{array}$ & $\mathrm{n}$ & $\begin{array}{l}\text { incidence rates } \\
\text { (per } 100,000 \\
\text { person-years) }\end{array}$ & $\mathrm{n}$ & $\begin{array}{l}\text { incidence rates } \\
\text { (per } 100,000 \\
\text { person-years) }\end{array}$ & $\mathrm{n}$ & $\begin{array}{l}\text { incidence rates } \\
\text { (per } 100,000 \\
\text { person-years) }\end{array}$ \\
\hline$<30$ years & 382 & 1.6 & 0 & 0.0 & 325 & 1.7 & 0 & 0.0 \\
\hline 30-39 years & 427 & 5.4 & 7 & 34.8 & 526 & 5.7 & 5 & 35.6 \\
\hline $40-49$ years & 1,013 & 13.2 & 10 & 29.5 & 1,253 & 13.8 & 28 & 30.1 \\
\hline $50-59$ years & 1,123 & 21.0 & 13 & 46.2 & 1,393 & 21.6 & 20 & 47.1 \\
\hline $60-69$ years & 332 & 27.4 & 3 & 47.6 & 412 & 27.0 & 4 & 47.4 \\
\hline All & 3,277 & 8.5 & 33 & 18.2 & 3,909 & 10.5 & 57 & 30.4 \\
\hline
\end{tabular}

(SIRs) were calculated for each period as the ratio of observed to expected number of cases. The expected number of cases was calculated for each age, sex, period, region, and socioeconomic status group. SIRs were calculated for offspring/sibling whose first-degree relatives (parents/siblings) had a subarachnoid hemorrhage; reference groups consisted of persons of the same sex and age group whose first-degree relatives had not experienced subarachnoid hemorrhage. The risks were adjusted for dependence. 95\% confidence intervals ( $95 \%$ CI) were calculated based on the SIRs assuming a Poisson distribution. Offspring were diagnosed for their first hospitalized subarachnoid hemorrhage at ages 0-69 years, whereas the age of parents at their diagnosis was not limited. For the reason of making the familial risks comparable with the age of the offspring population, we calculated the SIRs for offspring when parental age was limited to 69 years in table 3. Risks for siblings were calculated using the cohort method as described [28]. Shortly, we defined a cohort of individuals with at least 1 affected sibling and computed the incidence rates in this cohort over the study period. In a family with 2 or more affected siblings, each affected individual is included in the cohort (as the sibling of an affected individual). The incidence rates in the cohort method are given by the formula:

$$
\frac{\sum_{k=2}^{N} n_{k}}{\left[\sum_{k=1}^{N} p_{k}+\sum_{k=2}^{N} y_{k}\right]}
$$

Where $n_{k}$ is the number of affected individuals with $k$ affected siblings, $p_{k}$ the number of person-years contributed by unaffected individuals in families with $k$ affected siblings, and $y_{k}$ the number of person-years contributed by affected siblings in families with $k$ affected siblings, in the relevant age/sex/period/region/socioeconomic status category. The corresponding reference rates are given by:

$$
\frac{\sum_{k=1}^{N} n_{k}}{\left[\sum_{k=0}^{N} p_{k}+\sum_{k=1}^{N} y_{k}\right]}
$$

Confidence intervals (95\% CI) were calculated assuming a Poisson distribution, and they were adjusted for dependence between the sibling pairs [28]. Lower limits of 95\% CIs were quoted as 1 [29].

\section{Ethics Approval}

The research protocol was approved by the ethics committee of the Karolinska Institute.

\section{Results}

There were 3,277 incident cases of subarachnoid hemorrhage in men and 3,909 in women during the study period (table 1). Of these, $93.3 \%$ were obtained from the Swedish hospital discharge register and $6.7 \%$ were obtained from the cause of death register. The 30-day case fatality rate (i.e. the death rate among the hospitalized patients) was approximately $10 \%$ (data not shown). The incidence rate was 8.5/100,000 for men and 10.5/100,000 for women. The mean age at onset of subarachnoid hemorrhage was 45.7 years for men and 46.8 years for women. A total of 90 cases of subarachnoid hemorrhage were found in siblings, the proportion of cases with a sibling history of subarachnoid hemorrhage was $1.3 \%$. The incidence rate was about 2 times higher for men with a sibling history of subarachnoid hemorrhage than for those without such a history. For women with a sibling history of subarachnoid hemorrhage, the incidence rate was about 3 times higher than among women without a sibling history of the disease.

In figure 1, age-specific incidence rates of subarachnoid hemorrhage in men and women are plotted by sibling history. In general, the incidence rates of subarachnoid hemorrhage were much higher for those with a sibling history of the disease than for those without such a history. 


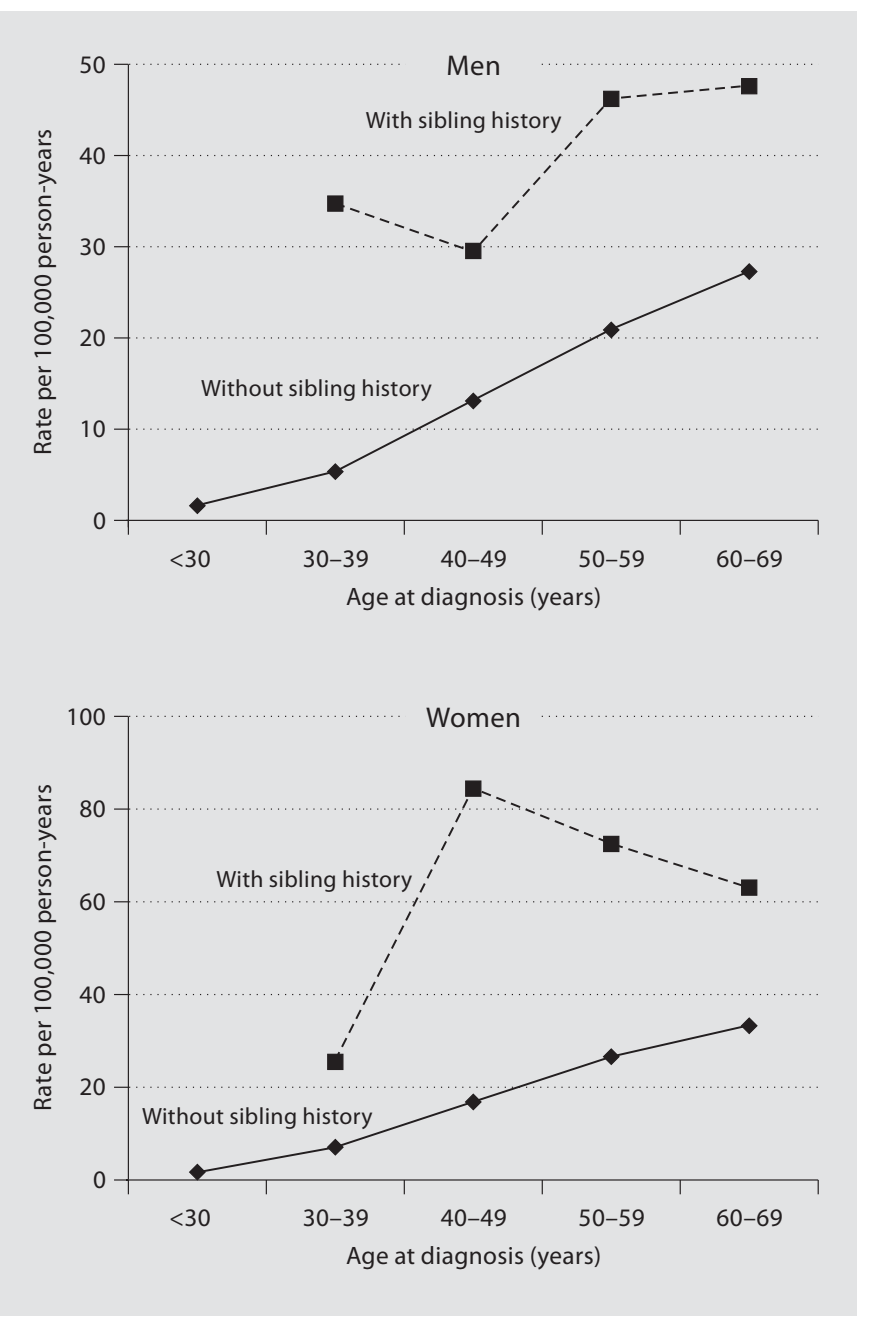

Fig. 1. Age-specific incidence rates of subarachnoid hemorrhage in men and women with and without sibling history of subarachnoid hemorrhage.

The SIRs of subarachnoid hemorrhage among persons who had at least 1 sibling with the disease are shown by age at diagnosis in table 2 . All models are adjusted for all the explanatory variables simultaneously, i.e., age, socioeconomic status, and geographical region. The overall SIR of subarachnoid hemorrhage among those who had at least 1 affected sibling was 2.23 (95\% CI 1.09-4.44) for men and 3.18 (95\% CI 1.70-5.83) for women, compared with the reference group of those without a sibling history. When 1 sibling was diagnosed before age 40 , the SIR was 4.11 (data not shown).

Table 3 shows familial risks and SIR ratios of subarachnoid hemorrhage in offspring when parents or siblings are probands. Parental age was limited to 69 years
Table 2. SIRs and observed number of cases of subarachnoid hemorrhage in men and women aged 0-69 years with siblings with subarachnoid hemorrhage ${ }^{1}$

\begin{tabular}{|c|c|c|c|c|c|c|}
\hline \multirow{2}{*}{$\begin{array}{l}\text { Age at diag- } \\
\text { nosis }\end{array}$} & \multicolumn{3}{|c|}{ Men } & \multicolumn{3}{|c|}{ Women } \\
\hline & $\mathrm{O}$ & SIR & $95 \% \mathrm{CI}$ & $\mathrm{O}$ & SIR & $95 \% \mathrm{CI}$ \\
\hline 30-39 years & 7 & 5.16 & $1.45-15.13$ & 5 & 3.20 & $0.71-10.63$ \\
\hline $40-49$ years & 10 & 1.81 & $0.61-4.72$ & 28 & 4.36 & $2.05-8.92$ \\
\hline 50-59 years & 13 & 2.20 & $0.83-5.35$ & 20 & 2.70 & $1.16-5.91$ \\
\hline $60-69$ years & 3 & 1.74 & $0.23-7.28$ & 4 & 1.91 & $0.35-6.98$ \\
\hline All & 33 & 2.23 & $1.09-4.44$ & 57 & 3.18 & $1.70-5.83$ \\
\hline
\end{tabular}

$\mathrm{O}=$ Observed number of cases. All models are adjusted for all the explanatory variables simultaneously, i.e., age, socioeconomic status, and geographical region. Italic type in the body of the table indicates that $95 \%$ CI does not include 1.00 .

${ }^{1}$ Reference groups consisted of persons of the same sex and in the same age group without a sibling history of subarachnoid hemorrhage.

Table 3. SIRs with $95 \% \mathrm{CI}$ and observed number of cases $(\mathrm{O})$ for subarachnoid hemorrhage in men and women aged $0-69$ years of parental and sibling probands

\begin{tabular}{llrll}
\hline Proband & $\begin{array}{l}\text { Age at } \\
\text { diagnosis, years }\end{array}$ & O & SIR & $95 \%$ CI \\
\hline Parents & $<50$ & 32 & 1.78 & $1.22-2.52$ \\
& $\geq 50$ & 3 & 1.40 & $0.26-4.13$ \\
& all & 35 & 1.74 & $1.21-2.43$ \\
Siblings & $<50$ & 50 & 3.36 & $1.76-6.27$ \\
& $\geq 50$ & 40 & 2.34 & $1.18-4.50$ \\
& all & 90 & 2.75 & $2.21-3.38$ \\
\hline & & & SIR ratio & p value \\
\hline SIR ratio & $<50$ & & 1.88 & 0.0063 \\
(sibling/parent) & $\geq 50$ & & 1.67 & 0.5309 \\
& all & & 1.58 & 0.0261 \\
\hline
\end{tabular}

Parental age at diagnosis was limited to 69 years. $\mathrm{O}=$ Observed number of cases.

${ }^{1} \mathrm{p}$ value, the probability of $\chi^{2}$ distribution based on the test statistic $\chi^{2}$ with 1 degree of freedom.

or younger to match the age range of the offspring population. The age at diagnosis of offspring was given at less than 50, 50 and over, and all, respectively. For offspring diagnosed before age 50 years, the SIR was 1.78 (95\% CI $1.22-2.52)$. The risk from a sibling proband was derived from the combined data as in table 2 . The SIR ratio was 
calculated by dividing the SIR (sibling proband) by the SIR (parental proband). The ratio was 1.58 for all subarachnoid hemorrhage and 1.88 at ages less than 50 years.

The SIRs for spouses who were incident for subarachnoid hemorrhage were also calculated (data not shown). The SIR for a husband/wife for subarachnoid hemorrhage was 1.06 ( $\mathrm{n}=19,95 \%$ CI 0.64-1.66) when the spouse was also hospitalized or died from the same reason.

\section{Discussion}

The main finding of this study was an overall observed sibling risk of 2.75, which is relatively high compared, for example, with most types of cancer [20,21].

The magnitude of increased risk of subarachnoid hemorrhage found in the current study is slightly lower than but overlaps with the findings of previous observational studies. In the present study, the risk of experiencing a subarachnoid hemorrhage was 2.23 for men who had at least 1 sibling with subarachnoid hemorrhage and 3.18 for women who had at least 1 affected sibling. Previous observational studies have demonstrated three- to sevenfold increased risks of subarachnoid hemorrhage in first-degree relatives (parents, siblings, children) of persons with subarachnoid hemorrhage [10, 13, 17].

The authors of a community-based study from Rochester, Minn. [13] identified 81 persons who had developed a subarachnoid hemorrhage between 1970 and 1989 and contacted their families for a family history. The Rochester study revealed an approximately fourfold increased risk of subarachnoid hemorrhage among first-degree relatives. In another study that also had a comparatively small study population, researchers in the Netherlands completed telephone interviews with all first- and second-degree relatives of 163 patients with subarachnoid hemorrhage. They found that 10 first-degree relatives of 9 patients had experienced subarachnoid hemorrhage. Thus, first-degree relatives had a 6.6 times raised risk of developing subarachnoid hemorrhage [10], an increase higher than that found in the current study. Some of the discrepancies between the current study and previous studies could be explained by recall bias.

In a population-based study, researchers in Denmark used national registries to study subarachnoid hemorrhage in 14,781 first-degree relatives of 9,367 persons with subarachnoid hemorrhage between 1977 and 1995 [10, 13, 17]. They found that 19 first-degree relatives of 18 persons with subarachnoid hemorrhage also experienced sub- arachnoid hemorrhage during the study period. This corresponded to an SIR of 2.9, a finding similar to that of the present study.

Familial clustering of a disease may be due to shared genes or shared environmental risk factors [20]. The present sibling results are higher than one would expect to find in parent-offspring pairs as a result of recessive inheritance patterns. We analyzed spouse risks, in part to examine the possibility of selection bias for hospitalization for subarachnoid hemorrhage among family members; most likely, the effect would be stronger for spouses than for adult siblings. The spouse correlation was low (SIR 1.06, 95\% CI 0.64-1.66), and only the small number of spouses prevents us from regarding these data as definite evidence against selection for hospitalization among siblings.

However, the available literature, given its limitations, lends no strong support to the hypothesis of a recessive mechanism [30,31]. A Finnish study of familial intracranial aneurysm identified 346 Finnish families with a least 2 members with intracranial aneurysms, and 329 of the total of $540(61 \%)$ were first-degree relatives [32]. Inheritance patterns found after analysis of $60 \%$ of the affected family members revealed autosomal recessiveness in $57 \%$, autosomal dominance in $36 \%$, and autosomal dominance with incomplete penetrance in 5.5\%. Although four genomewide linkage reports have documented the most interesting gene candidates, the variation in collagen and elastin type $1 \mathrm{~A} 2$ genes only clarifies a limited proportion of the genetic factors involved in intracranial aneurysms.

Many of the environmental risk factors for diseases such as subarachnoid hemorrhage are known to aggregate in families [33, 34]. However, modeling studies have indicated that even extreme frequency of smoking or other environmental/individual risk factors in families cannot explain more than a familial risk of about 1.3 [35], which is far below the 2.75 risk found in the current study. Even though other environmental risk factors correlate with smoking frequencies, it is unlikely that the known environmental risk factors would be the main explanation for the observed familial risk. Moreover, the environmental factors would be expected to account for the late-onset cases, whereas the heritable causes would contribute to the early-onset cases.

Numerous advantages accrued to the current study as a result of using the MigMed database. In most existing studies, information on family cases of subarachnoid hemorrhage is based on self-reported or proxy-reported data $[6,10,13,14,36]$. Such data can be subject to selec- 
tion and recall biases, thereby making quantitative estimates imprecise. Use of the MigMed database provided less opportunity for selection and avoided recall bias.

Data in the MigMed database are relatively complete. Information on occupational status, retrieved from the national census records in the database, was almost $100 \%$ complete (99.2\%). The same is true of hospital discharge data. In 2001, personal identification numbers were missing in only $0.4 \%$ and main diagnoses in $0.9 \%$ of hospitalizations.

We are confident that the accuracy level of the diagnostic data from the registers in the MigMed database is good. This data came from the cause of death register (6.7\% of subarachnoid hemorrhages) and the hospital discharge register (93.3\% of subarachnoid hemorrhages). A 1995 study assessing diagnostic accuracy in Swedish medical statistics found a good concordance between hospital discharge diagnoses and the underlying causes of death of those who were hospitalized and later died from 'dramatic conditions', such as diseases of arteries, arterioles, and capillaries; agreement was 89\% [37]. Moreover, a 1995 evaluation of the hospital discharge register undertaken by the Swedish National Board of Health and Welfare found that only $5 \%$ of myocardial infarction cases had an incorrect diagnosis [23]. However, accuracy is more difficult to achieve for rare causes of death, such as subarachnoid hemorrhages. Underreporting of somatic short-term care has been estimated at less than 2\% [24]. Another strength is that the reference group in the present study consisted of people with no first-degree relatives affected by subarachnoid hemorrhage whereas many previous studies assessed the incidence of subarachnoid hemorrhage in the total population and not simply in those with no affected first-degree relatives.

The current analysis has one important limitation: because the present data spanned only 15 years (1987-2001) we could consider only one generation of siblings. How- ever, previous research suggests that familial aneurysms rupture in the same decade of life in different family members. This would mean that a study based on a 15year period may accurately identify the relative risk of siblings of affected individuals although the overall lifetime risk may not be as high as our findings would suggest [38-40].

Additionally, it was not possible to differentiate between aneurismatic or nonaneurismatic subarachnoid hemorrhage. Another possible bias is that the cause of sudden death may in many cases be subarachnoid hemorrhage. These cases were not included in this study, which may lead to an underestimation of the calculated sibling risk.

In summary, using data on medically verified diagnoses and registered family structure, we showed a 2.75 -fold increase in subarachnoid hemorrhage among siblings of persons with subarachnoid hemorrhage in the 0- to 69year-old population. The risk decreased with increasing age in both men and women, indicating that it is also important for preventive efforts to focus on individual risk factors such as smoking $[2,16]$, alcohol consumption $[7$, 16], hypertension $[7,8,16]$, high hyperglycemia, and excessive weight [9], especially in young and middle-aged persons with an increased sibling risk.

\section{Acknowledgments}

This work was supported by grants from the National Institutes of Health (R01-H271084-1), the Swedish Research Council (K2004-21X-11651-09A and K2005-27X-15428-01A), and the Swedish Council for Working Life and Social Research (20012373). The authors wish to thank Kimberly Kane for useful comments on the text and Sanna Sundquist for technical assistance. This epidemiological study complies with the current laws of Sweden.

\section{References}

$\checkmark 1$ Sudlow CL, Warlow CP: Comparable studies of the incidence of stroke and its pathological types: results from an international collaboration. International Stroke Incidence Collaboration. Stroke 1997;28:491-499.

-2 van Gijn J, Rinkel GJ: Subarachnoid haemorrhage: diagnosis, causes and management. Brain 2001;124:249-278.

$\checkmark 3$ Zhang B, Fugleholm K, Day LB, Ye S, Weller RO, Day IN: Molecular pathogenesis of subarachnoid haemorrhage. Int J Biochem Cell Biol 2003;35:1341-1360.
4 Johnston SC, Selvin S, Gress DR: The burden, trends, and demographics of mortality from subarachnoid hemorrhage. Neurology 1998;50:1413-1418.

5 Pritchard C, Foulkes L, Lang DA, NeilDwyer G: Psychosocial outcomes for patients and carers after aneurysmal subarachnoid haemorrhage. Br J Neurosurg 2001;15: 456-463.

6 Schievink WI: Genetics of intracranial aneurysms. Neurosurgery 1997;40:651-662; discussion 662-653.
7 Juvela S: Alcohol consumption as a risk factor for poor outcome after aneurysmal subarachnoid haemorrhage. BMJ 1992;304: 1663-1667.

8 Morimoto M, Miyamoto S, Mizoguchi A, Kume N, Kita T, Hashimoto N: Mouse model of cerebral aneurysm: experimental induction by renal hypertension and local hemodynamic changes. Stroke 2002;33: 1911-1915. 
-9 Juvela S, Siironen J, Kuhmonen J: Hyperglycemia, excess weight, and history of hypertension as risk factors for poor outcome and cerebral infarction after aneurysmal subarachnoid hemorrhage. J Neurosurg 2005; 102:998-1003.

-10 Bromberg JE, Rinkel GJ, Algra A, Greebe P, van Duyn CM, Hasan D, Limburg $M$, ter Berg HW, Wijdicks EF, van Gijn J: Subarachnoid haemorrhage in first and second degree relatives of patients with subarachnoid haemorrhage. BMJ 1995;311:288-289.

-11 Teasdale GM, Wardlaw JM, White PM, Murray $\mathrm{G}$, Teasdale EM, Easton V: The familial risk of subarachnoid haemorrhage. Brain 2005;128:1677-1685.

-12 Norrgard O, Angquist KA, Fodstad H, Forsell A, Lindberg M: Intracranial aneurysms and heredity. Neurosurgery 1987;20:236239.

13 Schievink WI, Schaid DJ, Michels VV, Piepgras DG: Familial aneurysmal subarachnoid hemorrhage: a community-based study. J Neurosurg 1995;83:426-429.

- 14 De Braekeleer M, Perusse L, Cantin L, Bouchard JM, Mathieu J: A study of inbreeding and kinship in intracranial aneurysms in the Saguenay Lac-Saint-Jean region (Quebec, Canada). Ann Hum Genet 1996;60:99104.

-15 Ronkainen A, Hernesniemi J, Puranen M, Niemitukia L, Vanninen R, Ryynanen M, Kuivaniemi H, Tromp G: Familial intracranial aneurysms. Lancet 1997;349:380-384.

16 Schievink WI: Intracranial aneurysms. N Engl J Med 1997;336:28-40.

17 Gaist D, Vaeth M, Tsiropoulos I, Christensen K, Corder E, Olsen J, Sorensen HT: Risk of subarachnoid haemorrhage in first degree relatives of patients with subarachnoid haemorrhage: follow-up study based on national registries in Denmark. BMJ 2000;320: 141-145.

-18 Ruigrok YM, Rinkel GJ, Wijmenga C: Genetics of intracranial aneurysms. Lancet Neurol 2005;4:179-189.

-19 Hemminki K, Li X, Plna K, Granstrom C, Vaittinen P: The nation-wide Swedish family-cancer database: updated structure and familial rates. Acta Oncol 2001;40:772-777.
20 Hemminki K, Li X: Familial risks of cancer as a guide to gene identification and mode of inheritance. Int J Cancer 2004;110:291-294.

21 Hemminki K, Li X, Czene K: Familial risk of cancer: data for clinical counseling and cancer genetics. Int J Cancer 2004;108:109-114.

22 Hemminki K, Rawal R, Chen B, Bermejo JL: Genetic epidemiology of cancer: from families to heritable genes. Int J Cancer 2004;111: 944-950.

23 The National Board of Health and Welfare: Validity of the diagnoses from the Swedish In-Care register 1987 and 1995 (in Swedish). Epidemiologiskt Centrum, Socialstyrelsen, 2000. http://www.sos.se/epc/pdf/rapp8795. pdf.

24 Rosen M, Hakulinen T: Use of disease registers; in Ahrens W, Pigeot I (eds): Handbook of Epidemiology. Berlin, Springer, 2005.

25 Kunst AE, Groenhof F, Andersen O, Borgan JK, Costa G, Desplanques G, Filakti H, Giraldes M, Faggiano F, Harding S, Junker C, Martikainen P, Minder C, Nolan B, Pagnanelli F, Regidor E, Vagero D, Valkonen T, Mackenbach JP: Occupational class and ischemic heart disease mortality in the United States and 11 European countries. Am J Public Health 1999;89:47-53.

26 Hemingway H, Shipley M, Macfarlane P, Marmot M: Impact of socioeconomic status on coronary mortality in people with symptoms, electrocardiographic abnormalities, both or neither: the original Whitehall study 25 year follow-up. J Epidemiol Community Health 2000;54:510-516.

27 Lagerkvist L: Swedish Socioeconomic Classification: Reports on Statistical Co-Ordination (in Swedish). Örebro, Statistics Sweden, 1984.

28 Hemminki K, Vaittinen P, Dong C, Easton $\mathrm{D}$ : Sibling risks in cancer: clues to recessive or X-linked genes? Br J Cancer 2001;84:388391.

29 Newcombe RG: Two-sided confidence intervals for the single proportion: comparison of seven methods. Stat Med 1998;17:857-872.

30 Cannon Albright LA, Camp NJ, Farnham JM, MacDonald J, Abtin K, Rowe KG: A genealogical assessment of heritable predisposition to aneurysms. J Neurosurg 2003;99: 637-643.
Alexander JJ: The pathobiology of aortic aneurysms. J Surg Res 2004;117:163-175.

32 Wills S, Ronkainen A, van der Voet M, Kuivaniemi H, Helin K, Leinonen E, Frosen J, Niemela M, Jaaskelainen J, Hernesniemi J, Tromp G: Familial intracranial aneurysms: an analysis of 346 multiplex Finnish families. Stroke 2003;34:1370-1374.

33 Jonsson S, Thorsteinsdottir U, Gudbjartsson DF, Jonsson HH, Kristjansson K, Arnason S, Gudnason V, Isaksson HJ, Hallgrimsson J, Gulcher JR, Amundadottir LT, Kong A, Stefansson K: Familial risk of lung carcinoma in the Icelandic population. JAMA 2004;292: 2977-2983.

34 Madden PA, Pedersen NL, Kaprio J, Koskenvuo MJ, Martin NG: The epidemiology and genetics of smoking initiation and persistence: crosscultural comparisons of twin study results. Twin Res 2004;7:82-97.

35 Lorenzo Bermejo J, Hemminki K: Familial lung cancer and aggregation of smoking habits: a simulation of the effect of shared environmental factors on the familial risk of cancer. Cancer Epidemiol Biomarkers Prev 2005; 14:1738-1740.

36 Wang PS, Longstreth WT Jr, Koepsell TD Subarachnoid hemorrhage and family history: a population-based case-control study. Arch Neurol 1995;52:202-204.

37 Johansson LA, Westerling R: Comparing Swedish hospital discharge records with death certificates: implications for mortality statistics. Int J Epidemiol 2000;29:495-502.

38 Wiebers DO, Whisnant JP, Huston J 3rd, Meissner I, Brown RD Jr, Piepgras DG, Forbes GS, Thielen K, Nichols D, O'Fallon WM, Peacock J, Jaeger L, Kassell NF, Kongable-Beckman GL, Torner JC: Unruptured intracranial aneurysms: natural history, clinical outcome, and risks of surgical and endovascular treatment. Lancet 2003;362: 103-110.

-39 White PM, Wardlaw J: Unruptured intracranial aneurysms: prospective data have arrived. Lancet 2003;362:90-91.

40 Kailasnath P, Dickey P: ISUIA-II: the need to share more data. Surg Neurol 2004;62:95. 